\title{
Effect of Hydroxyzine and Meperidine on Arterial Blood Gases in Healthy Human Volunteers
}

\author{
Elemer K. Zsigmond, MD, FCP, Kathleen Flynn, and John G. Shively, MD
}

\begin{abstract}
Because hydroxyzine hydrochloride is frequently used to tranquilize patients, who are receiving narcotic analgesics for pain relief, its effect alone and in combination with meperidine on arterial blood gases and ventilation in patients at rest was evaluated in 65 healthy volunteers, who gave informed consent. Hydroxyzine hydrochloride, $1.5 \mathrm{mg} / \mathrm{kg}$ IV given over 30 seconds, caused no decrease but rather a significant $(\mathrm{P}<.001)$ increase in $\mathrm{PaO}_{2}$ and no increase in $\mathrm{PaCO}_{2}$ and/or $\mathrm{pH}$ at 5, 10, 20, 30, and 60 minutes $(\mathrm{N}=29$; mean age $=47.0$ years). Meperidine, $1.5 \mathrm{mg} / \mathrm{kg} I V$ given over 30 seconds, caused a significant $(\mathrm{P}<.01)$ reduction in $\mathrm{PaO}_{2}$ at 5 minutes indicating ventilatory depression but no increase in $\mathrm{PaCO}_{2}$ and/or $\mathrm{pH}(\mathrm{N}=19$; mean age $=32.4$ years). The combination of the same doses of hydroxyzine with meperidine IV caused a significantly greater decrease in $\mathrm{PaO}_{2}$ only at 10 minutes but a greater increase in $\mathrm{PaCO}_{2}$ and $\mathrm{pH}$ at all times for 60 minutes than did meperidine alone $(N=17$; mean age $=39.5$ years), which indicates greater ventilatory depression with the combination than with hydroxyzine alone. However, $\mathrm{PaO}_{2}, \mathrm{PaCO}_{2}$ and $\mathrm{pH}$ remained within the awake normal ranges for $\mathrm{PaO}_{2}, \mathrm{PaCO}_{2}$, and $\mathrm{pH}$ for the age group of volunteers even at 10 minutes after IV injection of the drug combination when most of the volunteers were asleep. In conclusion, hydroxyzine even when given IV in excess of the maximum IM therapeutic doses caused no changes in $\mathrm{PaO}_{2}$, $\mathrm{PaCO}_{2}$ or $\mathrm{pH}$, which would indicate clinically important ventilatory depression. Furthermore, blood gases remained in the normal awake range even after the combined IV administration of hydroxyzine and meperidine in excess of the maximum IM therapeutic doses.
\end{abstract}

$\mathbf{T}$ ranquilizers are used commonly to reduce anxiety and restlessness in psychiatric, critically ill, cardiac, and surgical patients and for ataract analgesia, an anesthetic technique based on the combined IV administration of tranquilizers and narcotic analgesics. Hence, it is essential to know if and to what extent a particular tranquilizer and/or narcotic analgesic alters blood gases and, consequently, ventilation. Narcotics are also frequently used as preanesthetic medications in surgical patients, especially in those who have pain before surgery. Some even believe that narcotic analgesics create a state of eu-

From the Department of Anesthesiology, University of Michigan Medical Center, Ann Arbor, Michigan, and the Division of Pulmonary Medicine, Allegheny General Hospital, Pittsburgh, Pennsylvania. This work was presented in part at the Annual Meeting of the American College of Clinical Pharmacology in 1966, Atlantic City, New Jersey. Address for reprints: E. K. Zsigmond, MD, Professor of Anesthesiology, University of Illinois Medical School, 1740 W. Taylor Street, Chicago, IL 60612. phoria and relaxation thereby alleviating fear and/ or anxiety. Because of the clinically important ventilatory depression caused by narcotic analgesics, we only use them if the patient requires them for pain relief. For tranquilization, we use tranquilizers that have specific action on the limbic system, for example, hydroxyzine, to allay apprehension before surgery and/or anesthesia, ${ }^{1}$ because a previous doubleblind study showed that hydroxyzine effectively relieved anxiety. ${ }^{2}$ To substantiate earlier reports on the lack of ventilatory depressant effects by hydroxyzine,$^{3.4}$ our clinical pharmacologic studies on arterial blood gases after IV hydroxyzine in healthy volunteers was undertaken.

The combination of tranquilizers and narcotic analgesics has been used frequently (IM or IV) to alleviate preoperative anxiety, fear and/or pain in surgical patients, and even in combination with barbiturates. Dangerous arterial hypoxemia, however, was observed after the combined IM use of narcotics, 
phenothiazines, and barbiturates in cardiac patients by Pierce and Garofalvo. ${ }^{5}$ This observation was not unexpected, because severe ventilatory depression associated with the use of narcotic analgesics has been well substantiated. ${ }^{6}$ Although ample studies were carried out on changes of respiratory center $\mathrm{CO}_{2}$ sensitivity to meperidine and hydroxyzine, ${ }^{4-9}$ no blood gas studies were as yet carried out either with tranquilizers alone, narcotic analgesics alone, or with combination of these drugs either in healthy humans or patients with pulmonary or cardiovascular diseases. Because blood gas determinations are used frequently in the evaluation of patients and of ventilatory adequacy, the information derived from our studies may facilitate the correct monitoring of patients, especially in the postoperative recovery room or intensive care units.

To determine the effect of drugs in combination, first each component should be studied separately in healthy humans and, furthermore, in patients with pulmonary or cardiovascular diseases. Therefore, hydroxyzine and meperidine were given alone and in combination IV to healthy volunteers with normal pulmonary function and no evidence of cardiac disease. The IV route was chosen for drug administration for two reasons: (1) IV administration more reliably achieves consistent and reproducible blood levels (and thereby the drug effect) than does IM administration, and (2) the peak blood levels after IV administration far exceed those expected and observed after IM administration, which is the most commonly used route of administration for both drugs. Consequently, if no respiratory depression results from IV administration of a tranquilizer or narcotic analgesic, the IM injection is not likely to lead to respiratory depression. Therefore, these clinical pharmacologic studies after IV administration of hydroxyzine and meperidine alone and in combination were undertaken in healthy volunteers and in patients with lung disease. The results of the latter study will be reported later.

\section{METHODS}

Sixty-five healthy volunteers, who signed a valid written consent and who were not undergoing drug treatment or who were not habituated to any drug, were selected for the study. The study was approved by the institutional review board. No minors or pregnant women were accepted. Of these patients, 29 volunteers with a mean age 47.0 years (range, 18 to 84 years) received hydroxyzine $1.5 \mathrm{mg} / \mathrm{kg}$ IV over 30 seconds, 19 volunteers with a mean age of 32.4 years (range, 19 to 62 years) received meperidine 1.5 $\mathrm{mg} / \mathrm{kg}$, and 17 volunteers with a mean age of 39.5 years (range, 19 to 70 years) received first hydroxyzine $1.5 \mathrm{mg} / \mathrm{kg} \mathrm{IV}$ over 30 seconds followed $2 \mathrm{~min}$ utes later by meperidine $1.5 \mathrm{mg} / \mathrm{kg}$ IV over $30 \mathrm{sec}-$ onds. In a special research unit, the volunteers were allowed to read or watch television unless they spontaneously fell asleep, which commonly occurred after the combination of hydroxyzine with meperidine or either drug alone. They were maintained in the supine position throughout the study.

After a 20-G Riley arterial needle was inserted into the brachial artery of the nonpreferred arm and an IV infusion of $5 \%$ glucose in $0.2 \%$ saline solution was started in the preferred arm, a period of rest was allowed. Two baseline arterial blood samples were then drawn at 20-minute intervals. If the two determinations differed less than $5 \%$, the study was begun.

For monitoring respiratory rate, a chest plethysmograph was attached, and a continuous recording was obtained on a Gilson polygraph. The brachial arterial blood pressure through a Statham strain gauge, lead II electrocardiogram, and phonocardiogram from the apex of the heart were also recorded on a Gilson polygraph, at least up to 1 hour after the last blood-gas sample to rule out adverse circulatory changes that might have altered blood gases.

After the first two baseline samples were obtained, each volunteer received the IV medication injected slowly over 30 seconds.

The oxygen tension was directly determined with a Clark oxygen electrode and the carbon dioxide tension by the method of Siggaard-Anderson on a Radiometer Copenhagen $\mathrm{pH}$ blood gas analyzer or on an Instrumentation Laboratory $\mathrm{H}-113 \mathrm{pH}$ blood gas analyzer twice before and at 5, 10, 20, 30, and 60 minutes after drug administration. The $\mathrm{pH}$ was directly measured with the glass electrode of the $\mathrm{pH}$ blood gas analyzer at the same time intervals.

Student's $t$ tests were used for statistical analysis of the data.

\section{RESULTS}

Hydroxyzine caused no reduction but, rather, a highly significant $(P<.001)$ increase in $\mathrm{PaO}_{2}$ for 30 minutes after its administration (Table I). A decrease in $\mathrm{PaCO}_{2}$ and no change in $\mathrm{pH}$ was observed at any time after its administration (Tables II and III). Meperidine caused a significant $(P<.01)$ reduction in $\mathrm{PaO}_{2}$ at 5 minutes (Figure) but no increase in $\mathrm{PaCO}_{2}$ and/or $\mathrm{pH}$ (Tables II and III). The combination of hydroxyzine with meperidine compared with meperidine alone caused a significant $(P<.01)$ greater decrease in $\mathrm{PaO}_{2}$ which peaked at 5 minutes and was 
TABLE I

\begin{tabular}{|c|c|c|c|c|c|c|c|}
\hline \multicolumn{8}{|c|}{$\mathrm{PaO}_{2}$ In Healthy Volunteers Given Hydroxyzine and Meperidine Alone and Their Combination } \\
\hline \multirow[b]{2}{*}{ Drugs } & \multirow[b]{2}{*}{ No. } & \multicolumn{6}{|c|}{ Mean $\pm \mathrm{SD} \mathrm{PaO}_{2}$ in $\mathrm{mm} \mathrm{Hg}$} \\
\hline & & $0 \mathrm{~min}$ & $5 \mathrm{~min}$ & $10 \mathrm{~min}$ & $20 \mathrm{~min}$ & $30 \mathrm{~min}$ & $60 \mathrm{~min}$ \\
\hline $\begin{array}{l}\text { Hydroxyzine } \\
(1.5 \mathrm{mg} / \mathrm{kg})\end{array}$ & 29 & $82.4 \pm 8.1$ & $86.9 \pm 7.2^{*}$ & $90.5 \pm 4.8^{* * *}$ & $89.4 \pm 5.8^{* * *}$ & $93.4 \pm 5.4^{* * *}$ & $78.4 \pm 5.7^{*}$ \\
\hline $\begin{array}{l}\text { Meperidine } \\
\quad(1.5 \mathrm{mg} / \mathrm{kg})\end{array}$ & 19 & $85.3 \pm 9.5$ & $73.8 \pm 9.5^{* *}$ & $80.6 \pm 11.1$ & $83.9 \pm 8.8$ & $82.3 \pm 9.3$ & $83.8 \pm 10.9$ \\
\hline $\begin{array}{l}\text { Hydroxyzine } \\
(1.5 \mathrm{mg} / \mathrm{kg}) \\
\text { and } \\
\text { meperidine } \\
(1.5 \mathrm{mg} / \mathrm{kg})\end{array}$ & 17 & $82.5 \pm 9.0$ & $70.0 \pm 13.6^{* *}$ & $71.4 \pm 8.9 * * \dagger \dagger$ & $79.4 \pm 8.5$ & $79.5 \pm 10.4$ & $76.1 \pm 9.2^{*} t$ \\
\hline $\begin{array}{l}\because P<.05 \text { as com } \\
\because * P<.01 \text { as co } \\
* * * P<.001 \text { as }\end{array}$ & $\begin{array}{l}\text { ared w } \\
\text { pared } \\
\text { ompar }\end{array}$ & $\begin{array}{l}0 \text { minute val } \\
h 0 \text { minute } v \\
\text { with } 0 \text { minute }\end{array}$ & & $\begin{array}{l}t P< \\
t+P \\
t+t P\end{array}$ & $\begin{array}{l}\text { as compared with } t \\
1 \text { as compared with } \\
001 \text { as compared w }\end{array}$ & $\begin{array}{l}\text { meperidine group. } \\
\text { e meperidine group. } \\
\text { the meperidine group. }\end{array}$ & \\
\hline
\end{tabular}

sustained until 20 minutes (Table I). Until 20 minutes, the respiratory depression caused by the combination was significantly greater than that caused by meperidine (Figure). The increase in $\mathrm{PaCO}_{2}$ and $\mathrm{pH}$ compared with the baseline after the administration of the combination was highly significant $(P$ $<.001$ ) at 10 and 20 minutes but remained elevated until 30 and 60 minutes, respectively $(P<.05)$ (Tables II and III, Figure). Until 20 minutes, the $\mathrm{PaCO}_{2}$ was significantly higher and the $\mathrm{pH}$ lower in the hydroxyzine-meperidine than in the meperidine group when the two groups were compared.

\section{DISCUSSION}

This is the first objective evaluation of blood gas changes following hydroxyzine hydrochloride that corroborated the previous reports ${ }^{3.4,7.10}$ that hydroxyzine hydrochloride causes no ventilatory depression in healthy humans in tranquilizing doses even when given IV rather than IM or orally in doses far in excess of doses considered optimal and safe in clinical practice. Hydroxyzine causes an increase rather than a decrease in $\mathrm{PaO}_{2}$, which is probably an expression of a lower metabolic rate and thereby lowered oxygen demand induced by tranquilization and sleep in most of the volunteers. This lack of decrease in $\mathrm{PaO}_{2}$ and increase in $\mathrm{PaCO}_{2}$ and/or $\mathrm{pH}$ confirms the results of Lauria et al. ${ }^{7}$ and of our previous double-blind study, that minute ventilation, respiratory rate, tidal volume, and $\mathrm{CO}_{2}$ response in healthy volunteers were not altered by hydroxyzine $1.5 \mathrm{mg} / \mathrm{kg} \mathrm{IM.}{ }^{7.10}$ Moreover, based on blood gas values, the lack of clinically important additive or potentiating effect of hydroxyzine on the ventilatory depression caused by meperidine makes it a safe tranquilizer for IM administration (note: hydroxyzine is not available for IV administration) to allay apprehension in patients in pain receiving meperidine IM, because the significant but modest decrease in $\mathrm{PaO}_{2}$ and increase in $\mathrm{PaCO}_{2}$ and $\mathrm{pH}$ with the IV combination did not exceed the normal range of values (Figure) for the age group of volunteers studied. Nor did the blood gas changes exceed the ranges observed in sleeping healthy individuals ${ }^{11.12}$ in any of the volunteers who received hydroxyzine with meperidine in combination. Of the 17 volunteers in this group, 15 fell asleep shortly after IV injection and slept for several hours but remained arousable by loud questions. Two volunteers required skin stimulation to be awakened in the first 20 minutes. Seldom, if ever, will such large IV doses be required except for surgical anesthesia. In routine clinical practice, hydroxyzine is administered IM or PO and meperidine IM and in lower optimal effective doses (50 mg), especially when combined. For our experiments for the determination of possible potentiation by hydroxyzine of the respiratory depression caused by meperidine, we did the following: (1) We selected the most reliable route of administration to achieve predictable blood levels, i.e., the IV route. (2) A sufficiently large IV dose $(1.5 \mathrm{mg} / \mathrm{kg})$ of meperidine was used, causing predictable and marked respiratory depression. (3) Doses of both drugs $(1.5 \mathrm{mg} / \mathrm{kg})$ were given; the amounts are unlikely to be exceeded even when given IM in clinical practice. We must em- 


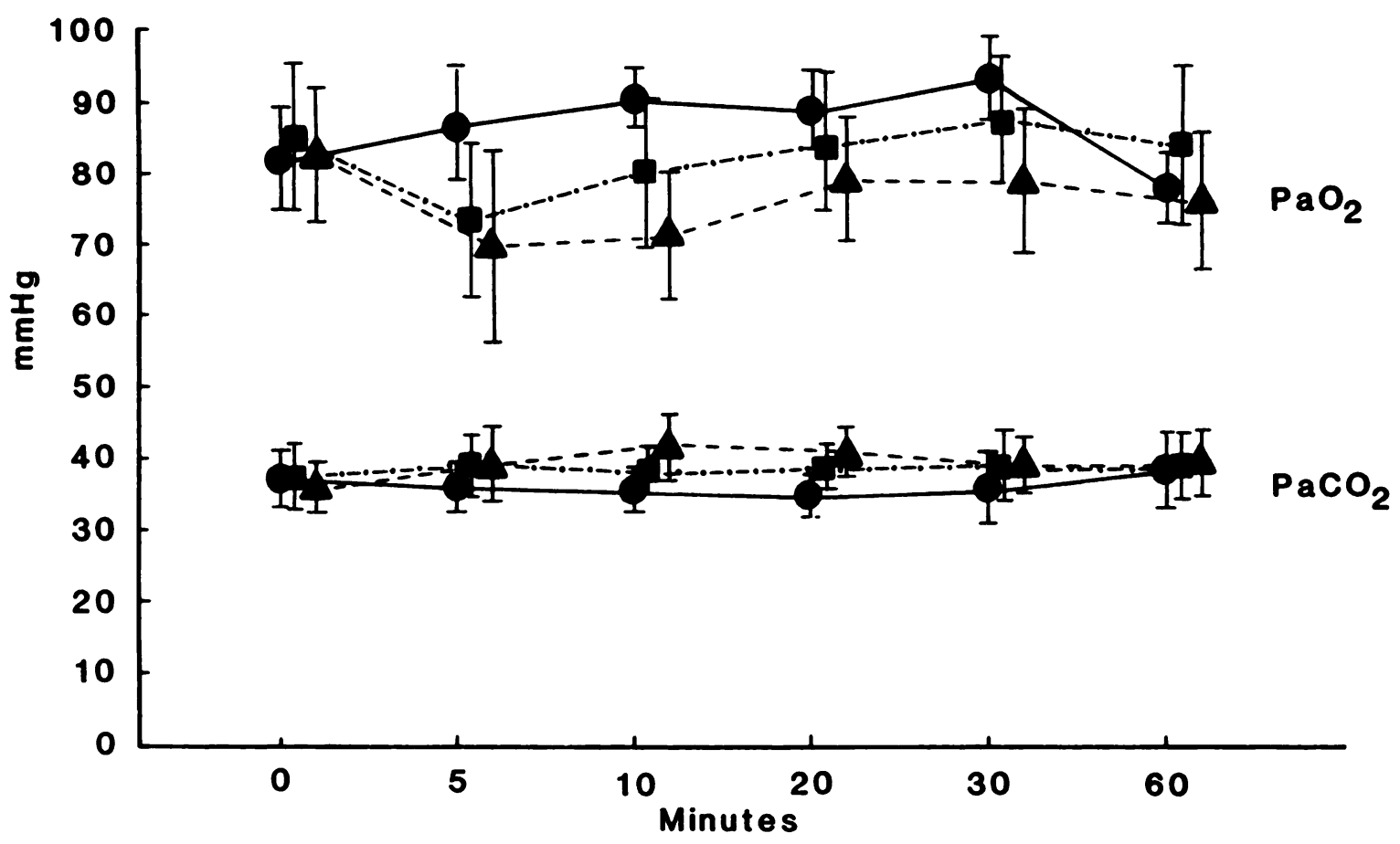

\author{
Hydroxyzine \\ Meperidine \\ Hydroxyzine-Meperidine combination
}

Figure. Arterial blood gas changes after IV administration of $1.5 \mathrm{mg} / \mathrm{kg}$ hydroxyzine, $1.5 \mathrm{mg} / \mathrm{kg}$ meperidine, and their combination. Upper lines represent $\mathrm{PaO}_{2}$ and lower lines represent $\mathrm{PaCO}_{2}$ (for statistical significance, see Tables).

phasize that we selected these large doses (1.5 $\mathrm{mg} / \mathrm{kg}$ ) only for the provocation of a potentiation of the meperidine-induced ventilatory depression by hydroxyzine in an experimental setting, and we do not recommend the IM use of these large doses, especially in combination, in clinical practice. Because hydroxyzine markedly potentiates analgesia, a $50 \mathrm{mg}$ IM dose is sufficient to produce optimal effect. $^{13}$

Since the completion of our study, no further studies on the effect of hydroxyzine and its combination with meperidine on arterial blood gases have been published. However, a few studies using a limited number of volunteers (three to five) were reported on the effect of hydroxyzine on the intercept and slope of respiratory response curve to $\mathrm{CO}_{2}$ with a refined, computerized method. ${ }^{14}$ In two of these studies, a detectable right shift in the $\mathrm{CO}_{2}$ response curve was observed, but the changes in the end-tidal $\mathrm{CO}_{2}$ pressure curve was less than $1.0 \mathrm{~mm} \mathrm{Hg}-0.84$ $\mathrm{mm} \mathrm{Hg}$ after $75 \mathrm{mg}$ hydroxyzine $\mathrm{IM}$ and $0.96 \mathrm{~mm} \mathrm{Hg}$ after $100 \mathrm{mg}$ hydroxyzine IV. ${ }^{8.9}$ However, some of the volunteers (2 out of 5) developed respiratory stimulation rather than depression in these studies. By the same refined assay, the right shift in $\mathrm{CO}_{2}$ response curve was quantitated as comparable to 4 mg morphine IV in healthy volunteers. ${ }^{15}$ Consequently, the authors concluded that the mild respiratory depression following hydroxyzine administration is of little clinical importance. ${ }^{9}$ Furthermore, the limited number of studied subjects limited the calculation of the significance of the findings of changes in slope and intercept. ${ }^{8}$ It is conceivable that the shift in $\mathrm{CO}_{2}$ response curves reported could be due to the reduction of sensory input to the respiratory center by the depression of the limbic system by hydroxyzine, although it is unclear from the reports how many of the volunteers fell asleep after hydroxyzine administration. In our investigation, $86 \%$ of the volunteers fell asleep and stayed asleep throughout the study period of 2 to 3 hours. It has been shown repeatedly that sleep per se reduces $\mathrm{PaO}_{2}$ and increases $\mathrm{PaCO}_{2}$ by 7 to $8 \mathrm{~mm} \mathrm{Hg}$ because of the reduction of the sensory input into the respira- 


\section{TABLE II}

\begin{tabular}{|c|c|c|c|c|c|c|c|}
\hline \multicolumn{8}{|c|}{$\mathrm{PaCO}_{2}$ In Healthy Volunteers Given Hydroxyzine and Meperidine Alone and Their Combination } \\
\hline \multirow[b]{2}{*}{ Drugs } & \multirow[b]{2}{*}{ No. } & \multicolumn{6}{|c|}{ Mean $\pm \mathrm{SO} \mathrm{PaCO}_{2}$ in $\mathrm{mm} \mathrm{Hg}$} \\
\hline & & $0 \mathrm{~min}$ & $5 \mathrm{~min}$ & $10 \mathrm{~min}$ & $20 \mathrm{~min}$ & $30 \mathrm{~min}$ & $60 \mathrm{~min}$ \\
\hline $\begin{array}{l}\text { Hydroxyzine } \\
(1.5 \mathrm{mg} / \mathrm{kg})\end{array}$ & 29 & $37.4 \pm 3.7$ & $36.1 \pm 2.3$ & $35.9 \pm 2.4$ & $35.3 \pm 2.6$ & $36.5 \pm 4.6$ & $39.4 \pm 4.2$ \\
\hline $\begin{array}{l}\text { Meperidine } \\
\quad(1.5 \mathrm{mg} / \mathrm{kg})\end{array}$ & 19 & $37.6 \pm 3.8$ & $39.0 \pm 3.2$ & $38.0 \pm 4.0$ & $38.5 \pm 3.3$ & $38.9 \pm 3.8$ & $39.2 \pm 3.8$ \\
\hline $\begin{array}{l}\text { Hydroxyzine } \\
(1.5 \mathrm{mg} / \mathrm{kg}) \\
\text { and } \\
\text { meperidine } \\
(1.5 \mathrm{mg} / \mathrm{kg})\end{array}$ & 17 & $36.0 \pm 3.5$ & $39.3 \pm 4.7^{*}$ & $41.9 \pm 3.8^{* * * t+t}$ & $40.8 \pm 2.8 * * * \dagger$ & $39.0 \pm 3.4^{*}$ & $39.3 \pm 4.4^{*}$ \\
\hline $\begin{array}{l}* P<.05 \text { as com } \\
\because P<.01 \text { as co } \\
\cdots P P<.001 \text { as }\end{array}$ & $\begin{array}{l}\text { ed wi } \\
\text { ared } \\
\text { npare }\end{array}$ & $\begin{array}{l}0 \text { minute value. } \\
\text { o minute value. } \\
\text { vith } 0 \text { minute valu }\end{array}$ & & $\begin{array}{l}t P<.0 \\
t+P<.0 \\
t+t P<\end{array}$ & $\begin{array}{l}\text { compared with the m } \\
\text { is compared with the } \\
1 \text { as compared with th }\end{array}$ & $\begin{array}{l}\text { eridine group. } \\
\text { peridine group. } \\
\text { neperidine group. }\end{array}$ & \\
\hline
\end{tabular}

tory centers. ${ }^{11}$ Contrary to these reports, Lauria et al. ${ }^{7}$ in a larger series of geriatric patients could not observe any depression of ventilation, determined by $\mathrm{CO}_{2}$ response curves after hydroxyzine IV, and five of ten subjects had respiratory stimulation rather than depression. The latter findings corroborate our observations on the lack of clinically important ventilatory depression by blood gas and spirometric studies in healthy volunteers and in patients with chronic obstructive lung diseases reported here and earlier in a pilot study. ${ }^{10}$
Because we showed previously that arterial blood gases were unaltered after atropine $0.6 \mathrm{mg} \mathrm{IV} \mathrm{in}$ healthy volunteers, ${ }^{16}$ despite contrary observations, ${ }^{17}$ the combination of hydroxyzine $1.5 \mathrm{mg} / \mathrm{kg}$ and atropine $0.008 \mathrm{mg} / \mathrm{kg}$ IM can also be used safely for routine preoperative medication or supplementation of local or nerve block anesthesia.

In conclusion, hydroxyzine $1.5 \mathrm{mg} / \mathrm{kg} \mathrm{IM}$ or $\mathrm{PO}$ may be used safely for premedication in place of analgesics in patients in whom respiratory depression should be avoided. Blood gas values remained

\section{TABLE III}

pH In Healthy Volunteers After Hydroxyzine, Meperidine, and Their Combination

\begin{tabular}{|c|c|c|c|c|c|c|c|}
\hline \multirow[b]{2}{*}{ Druges } & \multirow[b]{2}{*}{ No. } & \multicolumn{6}{|c|}{ Mean \pm SD pH } \\
\hline & & $0 \mathrm{~min}$ & 5 min & $10 \mathrm{~min}$ & $20 \mathrm{~min}$ & $30 \mathrm{~min}$ & $60 \mathrm{~min}$ \\
\hline $\begin{array}{l}\text { Hydroxyzine } \\
\quad(1.5 \mathrm{mg} / \mathrm{kg})\end{array}$ & 29 & $7.42 \pm 0.03$ & $7.42 \pm 0.02$ & $7.43 \pm 0.03$ & $7.42 \pm 0.03$ & $7.41 \pm 0.01$ & $7.42 \pm 0.04$ \\
\hline $\begin{array}{l}\text { Meperidine } \\
\qquad(1.5 \mathrm{mg} / \mathrm{kg})\end{array}$ & 19 & $7.39 \pm 0.02$ & $7.38 \pm 0.03$ & $7.38 \pm 0.03$ & $7.38 \pm 0.02$ & $7.38 \pm 0.02$ & $7.38 \pm 0.03$ \\
\hline $\begin{array}{l}\text { Hydroxyzine } \\
(1.5 \mathrm{mg} / \mathrm{kg}) \\
\text { and } \\
\text { meperidine } \\
(1.5 \mathrm{mg} / \mathrm{kg})\end{array}$ & 17 & $7.41 \pm 0.03 t$ & $7.38 \pm 0.04^{* *}$ & $7.36 \pm 0.02 * * * t$ & $7.36 \pm 0.01 * * * t+t$ & $7.40 \pm 0.04 \dagger$ & $7.40 \pm 0.04$ \\
\hline $\begin{array}{l}\because P<.05 \text { as con } \\
\because * P<.01 \text { as co } \\
* * * P<.001 \text { as }\end{array}$ & $\begin{array}{l}\text { ired } \\
\text { arec } \\
\text { mpal }\end{array}$ & $\begin{array}{l}\text { h } 0 \text { minute value. } \\
\text { ith } 0 \text { minute value } \\
\text { i with } 0 \text { minute va }\end{array}$ & & $\begin{array}{l}t P< \\
t+P< \\
t+t P<\end{array}$ & $\begin{array}{l}5 \text { as compared with the me } \\
01 \text { as compared with the m } \\
.001 \text { as compared with the }\end{array}$ & $\begin{array}{l}\text { eridine group. } \\
\text { peridine group. } \\
\text { meperidine group. }\end{array}$ & \\
\hline
\end{tabular}


in the normal range after the combined administration of $1.5 \mathrm{mg} / \mathrm{kg}$ of hydroxyzine with the same dose of meperidine even when given IV instead of IM to healthy volunteers. Therefore, the combination of hydroxyzine with meperidine by the IM route in lower doses than used in this IV study may be used safely in clinical practice without the hazard of clinically important ventilatory depression.

We are grateful to all the 65 volunteers, hospital employees, medical and paramedical personnel for volunteering for these studies conducted from June 1961 to September 1965 at Allegheny General Hospital, Pittsburgh, Pennsylvania. We greatly appreciate the generous support of Pfizer Laboratories, Inc., Pfizer Co., which made these studies possible.

\section{REFERENCES}

1. Zsigmond EK: Rational selection of preanesthetic medication for oral surgical patients. Oral Surg 1968;26:457-464.

2. Zsigmond EK, Patterson RL: Double-blind evaluation of hydroxyzine hydrochloride in obstetrical anesthesia. Anesth Analg 1967;46:275.

3. Weyne F, Roussel JL: Hydroxyzine in anesthesiology. Bruxelles Med 1957;37:1959.

4. Ponzi A, Tiengo M: Premedication with hydroxyzine in obstetric surgery, in Garattini S, Ghetti V (eds): Psychotropic Drugs. Amsterdam, Elsevier Publishing Co, 1957:571-572.

5. Pierce JA. Garofalvo ML: Preoperative medication and its effect on blood gases. JAMA 1965;194:487.

6. Eckenhoff JE, Helrich M, Hege JJD, Jones RE: Respiratory haz- ards of opiates and other narcotic analgesics. Surg Gynecol Obstet 1955;101:701.

7. Lauria JI, Markello R, King BD: Circulatory and respiratory effects of hydroxyzine in volunteers and geriatric patients. Anesth Analg 1968;47:378-382.

8. Gasser JC, Bellville JW: Interaction of the effects of hydroxyzine and pentazocine on human respiration. Anesthesiology 1975;43:599-601.

9. Gasser JC, Bellville JW: The respiratory effects of hydroxyzine, diazepam and pentazocine in man. Anesthesia 1976;31:718-723.

10. Zsigmond EK, Shively JG: Spirometric and blood gas studies on the respiratory effects of hydroxyzine hydrochloride in human volunteers (abstract). J New Drugs 1966;6:128.

11. Pierce AK, Jarrett CE, Werkle G Jr, Miller WF: Respiratory function during sleep in patients with chronic obstructive lung disease. J Clin Invest 1966;45:631-636.

12. Robin ED, Whaley RD, Crump $\mathrm{CH}$, Travis DM: Alveolar gas tensions, pulmonary ventilation and blood $\mathrm{pH}$ during physiologic sleep in normal subjects. J Clin Invest 1958;37:981.

13. Beaver WT, Feese G: Comparison of the analgesic effects of morphine, hydroxyzine and their combination in patients with postoperative pain. Adv Pain Res Ther 1976;1:533-537.

14. Bellville JW, Gilliland MC, Hara HH, Mower WE: Respiratory carbon dioxide response curve computer. Med Electron Biol Eng 1963;1:217-225.

15. Gabathuler ML, Kaufman RD: Respiratory depression of intravenous hydroxyzine in man: Potency, duration, and lack of reversal by naloxone. Anesth Analg 1981;60:634-637.

16. Finch JS, Zsigmond EK, DeKornfeld TJ: Arterial blood gases after atropine sulfate in healthy volunteers. Lancet 1969;2:773.

17. Tomlin PJ, Conway CM, Payne JP: Hypoxemia due to atropine. Lancet 1964;1:14. 